\title{
PENGARUH VARIASI KONSENTRASI DAN LAMA PERENDAMAN ASAM LAKTAT TERHADAP KANDUNGAN GLUKOSA DAN KUALITAS TEPUNG GANYONG (Canna Edualis Kerr) SEBAGAI PETUNJUK PRAKTIKUM BIOKIMIA
}

\author{
Erika Ayu Desanti ${ }^{1)}$. R.Bekti Kiswardianta ${ }^{2)}$, Nasrul Rofiah Hidayati ${ }^{3)}$. \\ ${ }^{1,)}$ SDK Advent Imanuel Madiun \\ ${ }^{2,3)}$ Program Studi Pendidikan Biologi FPMIPA IKIP PGRI Madiun, \\ Email:erika.desanti@yahoo.co.id \\ Diterima 20 September 2016 disetujui 24 Oktober 2016
}

\begin{abstract}
This study aims to investigate the influence of concentration and soaking time of lactic acid toward glucose and quality of canna's starch (Canna Edualis Kerr). The research method using a completely randomized design (CRD) with $3 \times 3 \times 3$ factorial and three replications. The repetition are K1L1, K1L2, $K 1 L 3, K 2 L 1, K 2 L 2, K 2 L 3, K 3 L 1, K 3 L 2$, first K3L3. The first factors is variations of concentration $(K)$ include $1 \%, 1.5 \%, 2 \%$, the second factor is soaking time $(L)$, there are 60 minutes, 90 minutes, 120 minutes. Collecting data by calculating the glucose level using titration method with Na. Organoleptic tests include color, odor, texture and level of preference to the 15 panelists using a closed questionnaire. Best organoleptic test are K3L3 treatment (2\% of lactic acid concentration with 120 minutes soaking time) with a total value of 82.5 while the lowest are K3L1 treatment (2\% of concentration with a 60 minutes of soaking time) with 48.5 of values. Data analysis shows the variation of concentration affect on glucose levels $(P=0.000<0.05)$. Soaking time affect on glucose levels $(P=0.000<0.05)$. There are any interaction effect of concentration and soaking time on glucose levels. Based on the results showed that the highest glucose levels found in K1LI treatment with $1 \%$ of lactic acid concentration and 60 minutes of soaking time. As for the glucose concentration was lowest for K3L3 treatment with $3 \%$ of lactic acid concentration and 120 minutes of soaking time. The results of this study are used as material preparation Biochemistry lab manual.
\end{abstract}

Keywords : lactic acid, Canna Edualis Kerr, soaking time, concentration, glucose content, lab manual

\section{PENDAHULUAN}

Ketergantungan masyarakat Indonesia pada produk tepung terigu sangat besar. Secara keseluruhan, produksi tepung terigu berasal dari gandum yang diimpor. Berdasarkan data Aptindo (2010), impor terigu tahun 2008 tercatat 530.914 ton, tahun 2009 angkanya naik menjadi 645.010 ton dan tahun 2010 menjadi 775.534 ton. Tahun 2011 sedikit menurun menjadi 680.125 ton (Feny, 2013). Jumlah dan pertumbuhan peduduk Indonesia saat ini cukup besar,sehingga tidak hanya mengandalkan pemenuhan kebutuhan sumber pangan karbohidrat hanya pada beras. Kesadaran untuk memanfaatkan pangan lokal sebagai bahan pangan pendamping sumber karbohidrat dari beras.

Ketergantungan masyarakat Indonesia pada produk tepung terigu sangat besar. Secara keseluruhan, produksi tepung terigu berasal dari gandum yang diimpor. Berdasarkan data Aptindo (2010), impor terigu tahun 2008 tercatat 530.914 ton, tahun 2009 angkanya naik menjadi 645.010 ton dan tahun 2010 menjadi 775.534 ton. 
Tahun 2011 sedikit menurun menjadi 680.125 ton (Feny, 2013). Jumlah dan pertumbuhan peduduk Indonesia saat ini cukup besar,sehingga tidak hanya mengandalkan

Upaya perbaikan mutu kualitas tepung ganyong dapat dilakukan dengan pegolahan yang lebih luas. Upaya perbaikan kualitas tepung dapat dilakukan dengan memodifikasi sifat- sifat fungsional. Modifikasi sebagai perubahan struktur molekul dari pati dapat dilakukan secara kimia, fisika, maupun enzimatis. Tepung termodifikasi kimia secara asam dibaut dengan cara menghidrolisis pati yang terdapat dalam tepung menggunakan asam. Reaksi dasar meliputi pemotongan ikatan a1,4-glikosidik dari amilosa dan a,1,6glikosidik dari amilopektin (Dwi,dkk, 2013).

Meskipun telah dikembangkan menjadi tepung, beberapa kelemahan dari sifat fungsional tepung ganyong masih ditemukan yang mengakibatkan masih rendahnya mutu dari tepung yang dihasilkan. Karena itu, perlu upaya perbaikan kualitas tepung ganyongperlu dilakukan. Perbaikan kualitas tepung perlu dilakukan agar penggunaanya sebagai bahan baku alternatif dalam pengolahan semakin luas. Dengan perbaikan kualitas ini diharapakn tepung ganyong dapat memiliki karakteristik yang diinginkan dan dapat diaplikasikan dalam pengembangan sebagai produk berbasis karbohidarat tinggi.

\section{METODE}

Penelitian ini dilakasanakan atau dilakukan di laboratorium IKIP PGRI Madiun. Bahan yang digunakan adalah umbi ganyong yang sudah tua, berkulit,coklat tua dan biasanya umbi sudah besar berdaging tebal.Yang banyak ditemukan didaerah sogaten yang banyak di perkebuanan warga. Bahan-bahan lain yang akan digunakan :
Larutan asam laktat dengan konsentrasi 1\%, $1,5 \%$ dan $2 \%$, air. Alat-alat yang digunakan dalam peneilitian ini adalah : Beaker Glass, Pipet tetes, Corong Glass, Labu Ukur 100 $\mathrm{ml}$, Pipet Volumetri $10 \mathrm{ml}, 20 \mathrm{ml}, \& 25 \mathrm{ml}$, Erlenmeyer, Refluks, Hot Plate, Gelas Ukur, Buret, Water Bath, Kertas Lakmus Biru.

Perlakuan yang pendahuluan pada praktikum ini adalah perendaman terhadap umbi ganyong dengan 3 perlakuan dan konsentrasi , lama perendaman asam laktat yang berbeda yaitu : $\mathrm{K}_{1} \mathrm{~L}_{1}, \mathrm{~K}_{1} \mathrm{~L}_{2}, \mathrm{~K}_{1} \mathrm{~L}_{3}$, $\mathrm{K}_{2} \mathrm{~L}_{1}, \mathrm{~K}_{2} \mathrm{~L}_{2}, \mathrm{~K}_{2} \mathrm{~L}_{3}, \mathrm{~K}_{3} \mathrm{~L}_{1}, \mathrm{~K}_{3} \mathrm{~L}_{2}, \mathrm{~K}_{3} \mathrm{~L}_{3}$.

Keterangan :

$\mathrm{K}_{1} \mathrm{~L}_{1}=$ Perlakuan kosentrasi $1 \%$ dengan lama perendaman 60 menit ; $\mathrm{K}_{1} \mathrm{~L}_{2}=$ Perlakuan kosentrasi $1 \%$ dengan lama perendaman 90 menit; $\mathrm{K}_{1} \mathrm{~L}_{3}=$ Perlakuan kosentrasi $1 \%$ dengan lama perendaman 120 menit; $\mathrm{K}_{2} \mathrm{~L}_{1} \quad=\quad$ Perlakuan kosentrasi $1,5 \%$ dengan lama perendaman 60 menit; $\mathrm{K}_{2} \mathrm{~L}_{2}=$ Perlakuan kosentrasi $1,5 \%$ dengan lama perendaman 90 menit; $\mathrm{K}_{2} \mathrm{~L}_{3}=$ Perlakuan kosentrasi 1,5\% dengan lama perendaman 120 menit; $\mathrm{K}_{3} \mathrm{~L}_{1}=$ Perlakuan kosentrasi $2 \%$ dengan lama perendaman 60 menit; $\mathrm{K}_{3} \mathrm{~L}_{2} \quad=$ perlakuan kosentrasi $2 \%$ dengan lama perendaman 90 menit; $\mathrm{K}_{3} \mathrm{~L}_{3}=$ Perlakuan kosentrasi $2 \%$ dengan lama perendaman 120 menit.

Setelah itu di tiriskan lalu dikeringkan, lalu digiling dan diayak suapaya lembut .Tepung dari dihasilakan dari berbagai perlakuan dianalisis dengan melihat warna, tekstur, bau d an kandungan glukosa.

Rancangan penelitian menggunakan pendekatan eksperimen. Pengujian dilakukan dengan metode Rancangan Acak Lengkap dengan 2 faktorial,variasi konsentrasi dan lama perendaman, Pengambilan sampel dilakukan dengan teknik Sampling acak (Random sampling), sehingga umbi ganyong (canna edualis kerr) sebagai anggota populasi dalam pengujian mempunyai peluang yang sama untuk menjadi anggota sampel penelitian . 
Data yang diambil dan diamati adalah data kadar kandungan glukosa dan kualitas tepung umbi ganyong. Uji kadar kandungan glukosa menggunakan hitungan rumus: Kadar Sakrosa $=(\%$ Gula setelah inversi - \% Gula sebelum Inversi ) X 0,95 \%, setelah mengetahui hasilnya dan dibandingakan dengan tabel angka penepatan kadar sakasora menurut luff-schoorl. Kualitas tepung umbi ganyong berdasarkan warna, tekstur, dan bau tepung yang dilakukan oleh 15 panelis menngunakan angket tertutup.

\section{HASIL DAN PEMBAHASAN}

Penelitian dari hasil uji glukosa dan uji organoleptik tepung ganyong.Dalam upaya berbaikan kualitas tepung ganyong sebagai bahan makanan alternatife pengganti tepung terigu. Berdasarkan hasil uji glukosa diperoleh data sebagai berikut Tabel 1. Uji kadar glukosa

\begin{tabular}{cccccc}
\hline \multirow{2}{*}{$\begin{array}{c}\text { Perla- } \\
\text { kuan }\end{array}$} & \multicolumn{3}{c}{ Ulangan } & $\begin{array}{c}\text { Rata- } \\
\text { rata }\end{array}$ & $\begin{array}{c}\text { Kadar } \\
\text { glukosa } \\
(\%)\end{array}$ \\
\hline $\mathrm{K}_{1} \mathrm{~L}_{1}$ & 19,3 & 19,3 & 19,2 & 19,2667 & $2,88 \%$ \\
$\mathrm{~K}_{1} \mathrm{~L}_{2}$ & 20,0 & 20,0 & 19,9 & 19,9667 & $2,04 \%$ \\
$\mathrm{~K}_{1} \mathrm{~L}_{3}$ & 20,0 & 20,2 & 20,1 & 20,1000 & $1,92 \%$ \\
$\mathrm{~K}_{2} \mathrm{~L}_{1}$ & 20,0 & 20,2 & 20,1 & 20,1000 & $1,92 \%$ \\
$\mathrm{~K}_{2} \mathrm{~L}_{2}$ & 19,6 & 19,8 & 19,9 & 19,7667 & $1,37 \%$ \\
$\mathrm{~K}_{2} \mathrm{~L}_{3}$ & 20,5 & 20,6 & 20,5 & 20,5333 & $1,32 \%$ \\
$\mathrm{~K}_{3} \mathrm{~L}_{1}$ & 20,5 & 20,4 & 20,7 & 20,5333 & $1,32 \%$ \\
$\mathrm{~K}_{3} \mathrm{~L}_{2}$ & 19,8 & 19,8 & 19,8 & 19,8000 & $1,25 \%$ \\
$\mathrm{~K}_{3} \mathrm{~L}_{3}$ & 19,8 & 20,0 & 20,3 & 20,0333 & $1,12 \%$ \\
\hline
\end{tabular}

Uji Glukosa menggambarkan bahwa rata-rata kadar glukosa tertinggi adalah 2,28 $\%$ pada perlakuan $\mathrm{K}_{1} \mathrm{~L}_{1}$ yaitu pada konsentrasi $1 \%$ dengan lama perendaman 60 menit. Sedangkan rata-rata kadar glukosa terendah adalah $1,12 \%$ pada perlakuan $\mathrm{K}_{3} \mathrm{~L}_{3}$ yaitu pada konsentrasi 2\% dengan lama perendaman 120 menit. Hasil uji hipotesis dengan menggunakan analisis 2 jalan menunjukkan bahwa variasi konsentrasi berpengaruh nyata terhadap kadar glukosa, pada variasi konsentrasi $2 \quad \% \quad\left(\mathrm{~K}_{3} \mathrm{~L}_{3}\right)$ memiliki kadar glukosa terendah yaitu $1,12 \%$.

Berdasarkan uji organoleptik diperoleh data sebagai berikut

Tabel 2. Uji organoleptik tepung ganyong

\begin{tabular}{cccccc}
\hline $\begin{array}{r}\text { Perla- } \\
\text { kuan }\end{array}$ & \multicolumn{3}{c}{ Uji Organoleptik } & $\begin{array}{c}\text { Jum- } \\
\text { lah }\end{array}$ & Nilai \\
\cline { 2 - 4 } & $\begin{array}{c}\text { Warna } \\
(40)\end{array}$ & $\begin{array}{c}\text { Bau } \\
(30)\end{array}$ & $\begin{array}{c}\text { Tekstur } \\
(30)\end{array}$ & & \\
\hline $\mathrm{K}_{1} \mathrm{~L}_{1}$ & 36,6 & 78,3 & 46,6 & 5211 & 52,1 \\
$\mathrm{~K}_{1} \mathrm{~L}_{2}$ & 75 & 40 & 50 & 5700 & 57 \\
$\mathrm{~K}_{1} \mathrm{~L}_{3}$ & 83,3 & 50 & 58,3 & 6581 & 65,8 \\
$\mathrm{~K}_{2} \mathrm{~L}_{1}$ & 61,6 & 61,6 & 55 & 5962 & 59,6 \\
$\mathrm{~K}_{2} \mathrm{~L}_{2}$ & 88,3 & 58,3 & 51,6 & 6829 & 68,3 \\
$\mathrm{~K}_{2} \mathrm{~L}_{3}$ & 40 & 75 & 56,6 & 5584 & 55,9 \\
$\mathrm{~K}_{3} \mathrm{~L}_{1}$ & 40 & 55 & 53,3 & 4849 & 48,5 \\
$\mathrm{~K}_{3} \mathrm{~L}_{2}$ & 76,6 & 76,6 & 66,6 & 7360 & 73,6 \\
$\mathrm{~K}_{3} \mathrm{~L}_{3}$ & 90 & 83,3 & 71,6 & 8247 & 82,5 \\
\hline
\end{tabular}

Warna merupakan komponen yang sangat penting untuk menentukan kualitas atau derajat penerimaan suatu bahan pangan. Suatu bahan pangan meskipun dinilai enak dan teksturnya sangat baik, tetapi memiliki warna yang kurang sedap dipandang atau memberi kesan telah menyimpang dari warna yang seharusnya, maka seharusnya tidak akan dikonsumsi.Hasil uji organoleptik warna menentukan kualitas tepung ganyong (Canna Edualis Kerr). yang mengacu pada skala hedonik yaitu 4 (Sangat putih), 3 (Putih), 2 (Tidak putih) dan 1 (Putih Kecoklatan). Perlakuan $\mathrm{K}_{3} \mathrm{~L}_{3}$ (konsentrasi asam laktat $2 \%$ dengan lama perendaman 120 menit) yang memiliki jumlah tertinggi yaitu 54, rata-rata tertinggi 3,6 dan nilai tertinggi 90 sedangkan pada perlakuan $\mathrm{K}_{1} \mathrm{~L}_{1}$ (Konsentrasi 1\% dengan lama perendaman 60 menit) yang memiliki jumlah terendah 22 , rata-rata terendah 1,3 dan nilai terendah 36,6 .

Hasil uji organoleptik terhadap aroma bertujuan untuk mengetahui tingkat respon dari panelis mengenai kesukaannya terhadap tepung ganyong (Canna Edualis Kerr). pada 
masing-masing perlakuan. Uji organoleptik bau adalah penilaian selanjutnya yang menentukan kualitas tepung tepung ganyong (Canna Edualis Kerr). yang mengacu pada skala hedonik yaitu 4 (tidak berbau), 3 (agak berbau ), 2 (kurang berbau) dan 1 (sangat berbau). Sesuai hasil histogram diatas menggambarkan, hasil uji organoleptik bau pada perlakuan $\mathrm{K}_{3} \mathrm{~L}_{3}$ (konsentrasi $2 \%$ dengan lama perendaman 120 menit) memiliki perlakuan dengan hasil paling tinggi, memiliki jumlah paling tinggi 50, rata-rata 3,3 dan nilai 83,3 Sedangkan pada perlakuan $\mathrm{K}_{1} \mathrm{~L}_{2}$ (Konsentrasi $1 \%$ sengan perendaman 90 menit) memiliki jumlah terendah yaitu 24, rata-rata 1,6 dan nilai 40 .

Tekstur merupakan sensasi tekanan yang dapat diamati dengan mulut (pada waktu digigit, dikunyah, dan ditelan) ataupun perabaan dengan jari. Sesuai gambar 4.2 mengambarkan, hasil uji organoleptik tekstur tepung ganyong (Canna Edualis Kerr) pada perlakuan $\mathrm{K}_{3} \mathrm{~L}_{3}$ (konsentrasi $2 \%$ dengan lama perendaman 120 menit) memiliki jumlah tertinggi yaitu 43, rata-rata 2,9 dan nilai 71,6 sedangkan pada perlakuan $\mathrm{K}_{1} \mathrm{~L}_{1}$ (konsentrasi $1 \%$ dengan lama perendaman 60 menit) menunjukkan jumlah terendah yaitu 28 , ratarata 1,9 dan nilai 4,6 setelah mengalami perlakuan. Hal tersebut menunjukkan bahwa konsentrasi berpengaruh terhadap tekstur tepung ganyong (Canna Edualis Kerr).

Berdasarkan hubungan uji glukosa dan uji organoleptik dapat diperoleh data sebagai berikut

\section{Hubungan antara uji glukosa dan uji organoleptik}

Hubungan antara uji glukosa dan uji organoleptik menggambarkan bagaimana hasil kandungan glukosa dengan uji organoleptik tepung ganyong terjadi perbedaan dimana kandungan Pada tepung ganyong paling tinggi terdapat pada perlakuan $\mathrm{K}_{1} \mathrm{~L}_{1}$ dengan perlakuan konsentrasi $1 \%$ dan lama perendaman 60 menit. Sedangkan kadar glukosa paling rendah terdapat pada perlakuan $\mathrm{K}_{3} \mathrm{~L}_{3}$ dengan perlakuan konsentrasi $2 \%$ dan lama perendaman 120 menit.

Tabel 3. Hubungan antara uji glukosa dan uji organoleptik

\begin{tabular}{lcc}
\hline \multirow{2}{*}{ Perlakuan } & \multicolumn{2}{c}{ Skor Nilai } \\
\cline { 2 - 3 } & $\begin{array}{c}\text { Uji } \\
\text { Organoleptik }\end{array}$ & Uji Glukosa \\
\hline $\mathrm{K}_{1} \mathrm{~L}_{1}$ & 52,1 & 22,8 \\
$\mathrm{~K}_{1} \mathrm{~L}_{2}$ & 57 & 20,4 \\
$\mathrm{~K}_{1} \mathrm{~L}_{3}$ & 65,8 & 19,2 \\
$\mathrm{~K}_{2} \mathrm{~L}_{1}$ & 59,6 & 19,2 \\
$\mathrm{~K}_{2} \mathrm{~L}_{2}$ & 68,3 & 13,7 \\
$\mathrm{~K}_{2} \mathrm{~L}_{3}$ & 55,9 & 13,2 \\
$\mathrm{~K}_{3} \mathrm{~L}_{1}$ & 48,5 & 13,2 \\
$\mathrm{~K}_{3} \mathrm{~L}_{2}$ & 73,6 & 12,5 \\
$\mathrm{~K}_{3} \mathrm{~L}_{3}$ & 82,5 & 11,2 \\
\hline
\end{tabular}

Berdasarkan data pada uji organoleptik hasilnya terbalik dengan hasil kadar glukosa yaitu pada uji organoleptik warna, bau, dan tekstur tepung ganyong (Canna Edualis Kerr) yang paling disukai oleh panelis adalah pada perlakuan $\mathrm{K}_{3} \mathrm{~L}_{3}$ dengan konsentrasi $2 \%$ dan lama perendaman 120 menit yang memiliki jumlah nilai 82,5,Sedangkan yang tidak disukai oleh panelis pada perlakuan $\mathrm{K}_{3} \mathrm{~L}_{1}$ dengan konsentrasi $2 \%$ dan lama perendaman 60 menit dengan jumlah nilai 48,5 .

\section{SIMPULAN}

Dari hasil penelitian terdapat pengaruh variasi konsentrasi dan lama perendaman asam laktat terhadap kadar glukosa dan kualitas pada tepung ganyong (Canna Edualis Kerr) dapat diambil kesimpulan sebagai berikut :

Variasi konsentrasi dan lama perendaman asam laktat memberikan pengaruh terhadap kadar glukosa pada 
tepung ganyong (Canna Edualis Kerr),dimana terdapat pada perlakuan $\mathrm{K}_{1} \mathrm{~L}_{1}$ ( konsentrasi $1 \%$ dengan lama perendaman 60 menit ) hasil dari kandungan glukosa paling tinggi yaitu 22,8, sedangkan pada perlakuan $\mathrm{K}_{3} \mathrm{~L}_{3}$ (Konsentrasi $2 \%$ dan lama perendaman 120 menit) hasil uji glukosa paling rendah yaitu 11,2.

Terdapat interaksi antara variasi konsentrasi dan lama perendaman terhadap kadar glukosa tepung tepung ganyong (Canna Edualis Kerr).

Variasi konsentrasi dan lama perendaman asam laktat memberikan pengaruh terhadap kualitas (warna, bau, tekstur) pada tepung ganyong (Canna Edualis Kerr).Dan dari hasil uji organoleptik dapat diambil data pada perlakuan $\mathrm{K}_{3} \mathrm{~L}_{3}$ (Konsentrasi $2 \%$ dan lama perendaman 120 menit) nilai yang tinggi yaitu 82,5 , sedangkan pada perlakuan $\mathrm{K}_{3} \mathrm{~L}_{1}$ (konsentrasi 2\% dengan lama perendaman 60 menit) hasil yang didapat semakin rendah yaitu 48,5.Karena semakin tinggi konsentrsi asam laktat dan lama perendaman maka semakin tinggi kualitas tepung ganyong (Canna Edualis Kerr).

\section{DAFTAR PUSTAKA}

Alsuhendra, dan Ridawati. (1995). Pengaruh Modifikasi Secara Pregelatinisasi, Asam,Dan Enzimatis terhadap Sifat Fungsional Tepung Umbi Gembili (Dioscorea esculenta ).PS Tata Boga Jurusan IKK FT .UNJ Kampus UNJ Rawamangun. Jakarta.

Cahyadi Wisnu, (2009). Bahan Tambahan Pangan. Analisis Dan Aspek Kesehatan. Perpustakaan Nasioanal, PT. Bumi Aksara.Jakarta.

Hartini Dwi Feny, dkk. (2013). Kajian Karakteristik Fisiokimia Tepung
Sukun (Artocarpus Communis ) Termodifikasi dengan Variasi Konsentrasi dan Lama Perendaman Asam Laktat. Jurusan Teknologi Pertanian Universitas Sebelas Maret Santyasa Wayan I. (2007). Pedoman

Penyusun Petunjuk Praktikum. Makalah workshop Media Pembelajaran . Banjarangkan Klungkung

Slamet Agus ,(2010). Pengaruh Perlakuan

Pendahuluan Pada Pembuatan Tepung ganyong ( Canna Edulis Kerr ) Terhadap Sifat Fisik Dan Amilografin Tepung Yang Dihasilkan. Program Studi Teknologi Hasil Pertanian, Falkultas Agroindustri Universitas Mercu Buana Yogyakarta.

Winarno, G. (1997). Kimia Pangan dan Gizi. Staf Pengajar Falkultas Teknologi Pertanian dan Fakultas Pasca Sarjana, Institut Peratanian Bogor.

Yanuwardana, dkk. (2013). Kajian Karakteristik Fisikokimia tepung Labu Kuning( Cucurbita moschata) Termodifikasi dengan Variasi Lama Perendaman dan Konsentrasi Asam Laktat. Jurusan Teknologi Hasil . Pertanian,Falkutas Pertanian, UniversitasSebelas Maret,Surakarta Yulfia, dkk. (2012). Keragaan Pertumbuhan Ganyong (Canna Edulis Kerr) pada Berbagai Ketinggian Tempat Berdasarkan Ciri Morfologi Di Kabupaten Bengkulu Selatan. Program. Studi Pasca Sarjana Pengelolaan Sumberdaya Alam dan Lingkungan, Fakultas Pertanian, Universitas Bengkulu. 